[Bull. Agr. Chem. Soc. Japan, Vol. 21, No. 3, p. 204 206, 1957]

\title{
Microdetermination of Parathion
}

Sir :

In the research for sea and river water contamination and damages of marine organisms caused by insecticides, there is a keen need for highly sensitive and specific methods for the determination of insecticides, especially parathion on account of its great toxicity. Several published spectrophotometric methods for parathion determination are based on the absorbances of parathion itself $\left(\lambda_{\max }\right.$. $\left.274 \mathrm{~m} \mu, \varepsilon 9.0 \times 10^{3}\right),{ }^{1)^{2)}}$ and $p$-nitrophenate ion $\left(\lambda_{\max .} 405 \mathrm{~m} \mu, \varepsilon 2.1 \times 10^{4}\right)^{3) 4}$ and on the color of azo dyes $\left(\lambda_{\max } 560 \mathrm{~m} \mu, \varepsilon 4.7 \times 10^{4}\right.$ s) and $\lambda_{\max }$. $\left..510 \mathrm{~m} \mu, \varepsilon 1.7 \times 10^{4} 6\right)$.

From the results of the preliminary tests conducted in this laboratory for phosphorus compound determination, the method of Soyenkoff $\left.\left(\lambda_{\max } .510 \mathrm{~m} \mu, \varepsilon 6.1 \times 10^{4}\right)^{7}\right)$ and its modified one of this laboratory $\left(\lambda_{\text {ruax }}\right.$. $\left.480 \mathrm{~m} \mu, \varepsilon 1.5 \times 10^{5}\right)$ have been employed. As the results, the following two procedures have been designed as the highly sensitive and specific methods for the estimation of small amounts of parathion which are contained in water. The basic steps of Method 1 for the concentration order of p.p.h.m. or more are: (1) Extraction, (2) reduction, (3) development and evaluation of an azo dye color, (4) digestion of an azo dye, (5) estimation of phosphorus. Those of Method 2 for the concentration order of p.p.b. are: (1) Extraction, (2) condensation and feeding on a paper strip, (3) paper chromrtography with non-aqueous solvent system, (4) elution of the spot, (5) digestion of paration, (6) colori-

\footnotetext{
1) American Cyanamide Company, Agricultural Chemicals Divi-

sion: Manual of Manufacturing Information for Thiophos (1952).

2) M. Kotakemori, Ann. Takamine Lab., Japan, 6, 146 (1954).

3) J.A.A. Ketelaar, and J. E. Hellingman, Anal. Chem, 23, 646 (1951).

4) K. O'Keefe, and P.R. Averell, ibid. 23, 1167 (1951).

5) P.R. Averell, and M.V. Norris, ibid. 20, 753 (1948).

6) J.C. Gage, Ana'yst, 75, 189 (1950).

7) B.C, Soyenkoff, Biot, Chem., 198, 221 (1952).
}

metry of phosphorus.

Procedure: Method 1-One liter of the sample is added with $17 \mathrm{ml}$ of concentrated hydrochloric acid and $50 \mathrm{~g}$ of sodium chloride, and extracted one time with each of $100 \mathrm{ml}$ and then $50 \mathrm{ml}$ portions of $n$-hexane, using a separatory funnelt. The combined hexane layer is filtered and evaporated just to dryness with a modified Kohn's rotating evaporators) or an agitating evaporator designed in this laboratory. To the residue are added $10 \mathrm{ml}$ of glacial acetic acid, 5 drops of concentrated hydrochloric acid and $0.3 \mathrm{~g}$ of zinc dust, and the mixture is gently boiled for 10 minutes. After cooling, it is filtered with suction, then the residue washed with $3 \mathrm{ml}$ of glacial acetic acid. The combined filtrate is cooled and added with $0.5 \mathrm{ml}$ of $0.5 \%$ sodium nitrite, $0.5 \mathrm{ml}$ of $5 \%$ ammonium sulfamate and $2 \mathrm{ml}$ of $1 \% \mathrm{~N}$-(1-naphthyl)ethylenediamine hydrochloride solution mixing them well in this order with each 15-minute interval under cooling at about $4^{\circ}$. The colored solution is made up to $20 \mathrm{ml}$ with glacial acetic acid and kept at about $25^{\circ}$. After standing for 30 to 60 minutes, the color at $560 \mathrm{~m} \mu$ is measured. Then, the azo dye solution transferred to an Erlenmyer flask is evaporated to about $10 \mathrm{ml}$ with flowing air immersing the flask partially in a water bath maintained at $95^{\circ}$. The condensate is evaporated to dryness in a digestion tube $(20 \times 250 \mathrm{~mm}$, borosilicate glass $)$ and digested with 10 drops of concentrated sulfuric acid and 7 drops of 30\% hydrogen peroxide at $155^{\circ}$ (oil bath) for 80 minutes. At the end of digestion, each tube is added with $5 \mathrm{ml}$ of water, heated in a boiling water bath for 10 minutes, neutralized, then made

\footnotetext{
$t$ If necessary, $5 \mathrm{ml}$. of $10 \%$ alum solution should be added to precipitate the impurities.
}

8) P. Kohn,: Anal. Chem., 28, 1061 (1956). 
up to $10 \mathrm{ml}$. A two-ml aliquot of this solution is added with $2 \mathrm{ml}$ of the dye solution (ethosulfate of 2- $p$-dimethylaminostyrylquinoline), then $1 \mathrm{ml}$ of the molybdate-sulfate solution, according to the method of Soyenkoff.

The optical density at $510 \mathrm{~m} \mu$ is read after 10 minutes. The two colorimetric data of the sample, absorbances of the azo dye and phosphorus color complex, are corrected by those of the blanks, respectively. The estimates of the paration content obtained by the aid of each standard curve from the azo dye and phosphorus colorimetries can be ascertained by the agreement of these two values. If these were discrepancy between them, the lower value should be chosen as the upper limit of the paration content.

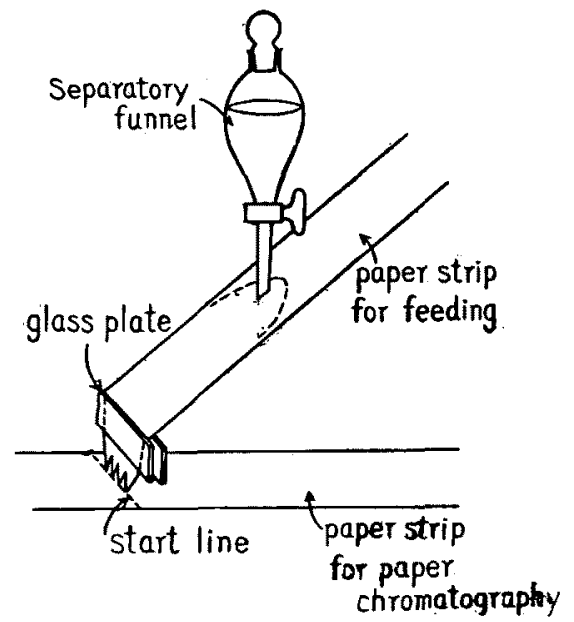

FIG. 1. Total Sample Feeder for Paper Chromatography.

Method 2-About $15 \mathrm{ml}$ of the condensate of the hexane layer obtained from 1 liter of the sample by the same treatment as Method 1 are feeded on a start line of a paper strip for paper chromatography. A total sample feeder for paper chromatography illustrated in Fig. 1 serves for feeding within the narrow area on the paper strip. As for paper chromatographic techniques, the descending method with methanol-hexane $(1: 2 \mathrm{v} / \mathrm{v})$

TABle I. $R_{F}$ Values of Parathion AND RELATED COMPOUNDS

Compound

Parathion, laboratory

Parathion, commercial

Emulsifier of Parathion

Methylparathion

Chlorthion

Echylchlorthion

4124 (isochlorthion)

Ethyl 4124

O-(2-nitrophenyl)-O, O-diethyl $0.24,0.35,0.63,0.71$ thiophosphate**

$\begin{array}{ll}\text { Malathion } & 0.02^{*} \\ \text { Diazinon } & 0.01^{*} \\ \text { TEPP } & 0.05^{*} \\ \text { Adenosinetriphosphate } & 0^{*} \\ \text { Ethylthiophosphate } & 0.01^{*} \\ \text { Methylthiophosphate } & 0^{*} \\ \text { Orthophosphoric acid } & 0^{*} \\ \text { Pyrophosphoric acid } & 0^{*}\end{array}$

mobile phase, hexane layer; stationary phase, methanol layer development of spot :

* sprayed $\mathrm{FeCl}_{3}$ and sulfosalicylic acid reagents; the others, alcoholic potassium hydroxide.

* * decomposed sample

system is employed t†. The $R_{F}$ value of pure parathion is $0.7-0.8$, and a sample of commercial parathion gives four spots developed by alcoholic potassium hydroxide with a yellow color which is due to a $p$-nitrophenate ion. The spot of parathion cut off by guiding of its authentic sample is eluted with the descending flow of about $10 \mathrm{ml}$ of acetone. The eluate is evapolated to dryness. The residue is digested with 3 drops of concentrated sulfuric acid and 2 drops of $30 \%$ hydrogenperoxide containing no phosphorus compound as the stabilizer at $155^{\circ}$ for 80 minutes in the oil bath. The tube-wall should be carefully rinsed with the digestion reagent by rotating the tube in advance of digestion. At the end of digestion, each tube is cooled, added with $0.5 \mathrm{ml}$ of diluted perchloric acid $\left(2.5 \mathrm{ml}\right.$ of $60 \% \mathrm{HClO}_{4}+50 \mathrm{ml}$ of

i† Metcalf and March's have reported a procedure involving reversed phase paper chromatography and colorimetry of phosphorus, but their method is not practical in this case.

9) R.L. Metcalf, and R.B. March, Sicience 117, 527 (1953). 
water), and then neutralized by $5 \mathrm{~N}$ sodium hydroxide using the phenolphthaleine solution as an indicator. After acidifying with 1 drop of $0.5 \mathrm{~N}$ sulfuric acid, the solution is made up to $2 \mathrm{ml}$. Two $\mathrm{ml}$ of the dye solution and then $1 \mathrm{ml}$ of the molybdate-sulfate solution are added under agitation. The
The authors wish to thank the National Institute of Agricultural Sciences, the Agricultural Chemical Inspection Station of the Ministry of Agriculture and Forestry, Sumitomo Chem. Ind. Co., Tōa Agr. Chem. Co., and Tôhō Chem. Ind. Co. for supplying the sample. This study is supported by a grant of the

Table II. Analytical Data

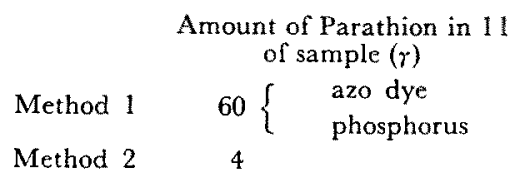

optical density at $480 \mathrm{~m} \mu$ is read exactly 5 minutes after the addition of the last reagent against a blank from 1 liter of water similarly treated. The parathion content of the sample is obtained by referring the absorbancy at $480 \mathrm{~m} \mu$ to a calibration curve.

The analytical data are shown in Table II. The results concerning the above two methods will be reported in detail later.

$\begin{array}{ccc}\text { Mean of four Absorbances } & \begin{array}{c}\text { Coefficient of } \\ \text { Variation(\%) }\end{array} & \begin{array}{c}\text { Recovery } \\ (\%)\end{array} \\ 0.481 \text { (at } 560 \mathrm{~m} \mu) & 0.8 & 98.8 \\ 0.160 \text { (at } 510 \mathrm{~m} \mu) & 2.4 & 99.0 \\ 0.432 \text { (at } 480 \mathrm{~m} \mu) & 2.8 & 89.0\end{array}$

Ministry of Agriculture and Forestry.

Yusuke Sumiki

Akira Matsuyama.

Hiromichi Kato

Yushih Chen

Teiji Yamauahr

Department of Agricultural Chemisiry. Facully

of Agricullure, University of Tokyo

Received April 8, 1957 